\title{
Understanding variability in hospital-specific costs of coronary artery bypass grafting represents an opportunity for standardizing care and improving resource use
}

\author{
Arman Kilic, MD, Ashish S. Shah, MD, John V. Conte, MD, Kaushik Mandal, MBBS, \\ William A. Baumgartner, MD, Duke E. Cameron, MD, and Glenn J. R. Whitman, MD
}

Background: This study was undertaken to examine interhospital variability in inpatient costs of coronary artery bypass grafting $(\mathrm{CABG})$.

\begin{abstract}
Methods: The Nationwide Inpatient Sample was used to identify isolated CABGs performed between 2005 and 2008 in the United States. Charges for inpatient care were supplied by the data set, and hospital charge-to-cost ratios were used to derive inpatient costs for each patient and aggregated at the hospital level. Mixed-effect linear regression models were created to evaluate variability in costs between hospitals adjusting for 34 patient, operative, complication, and hospital-related variables.
\end{abstract}

Results: A total of 633 hospitals performed isolated CABG in 183,973 patients. In unadjusted analysis, there was significant baseline variability in average inpatient costs of CABG between hospitals (SD, \$12,130; $P<.001)$. This variability represented $30 \%$ of the overall unadjusted average cost of performing CABG per hospital $(\$ 40,424)$. After risk adjustment, significant variability in average costs between hospitals persisted $(P<.001)$. Of the 34 additional variables included in the model, only hospital region, postoperative sepsis, in-hospital mortality, and need for ventricular assist device, extracorporeal membrane oxygenation, permanent pacemaker, or implantable cardioverter-defibrillator were stronger predictors of increased costs compared with the hospital effect.

Conclusions: There is a wide variation in the cost of performing CABG in the United States. We determined that individual hospital centers, independent of multiple patient- and outcome-specific factors, are drivers of these differences. Comparison of hospital-specific behavior with identification of the causes of cost discrepancies represents an opportunity for standardization of care and improvement in resource use. ( $\mathrm{J}$ Thorac Cardiovasc Surg 2014;147:109-16)

Health care spending in the United States continues to garner interest by multiple parties, including individual providers, hospitals, policy makers, and the public. Despite higher costs, the quality of care provided in the United States has not been demonstrated to be measurably superior to that in other countries. ${ }^{1}$ This has underscored the importance of cost containment and specific strategies to reduce health care spending.

These themes apply specifically to coronary artery bypass grafting $(\mathrm{CABG})$ as well. $\mathrm{CABG}$ represents one of

\footnotetext{
From the Division of Cardiac Surgery, Department of Surgery, The Johns Hopkins Medical Institutions, Baltimore, Md.

This study was supported by departmental funds from the Department of Surgery, Johns Hopkins Hospital, Baltimore, Md.

Disclosures: Authors have nothing to disclose with regard to commercial support. Read at the 93rd Annual Meeting of The American Association for Thoracic Surgery, Minneapolis, Minnesota, May 4-8, 2013.

Received for publication May 6, 2013; revisions received July 28, 2013; accepted for publication Aug 9, 2013; available ahead of print Oct 7, 2013

Address for reprints: Glenn J. R. Whitman, MD, Division of Cardiac Surgery, Johns Hopkins Hospital, 1800 Orleans St, Sheikh Zayed Tower Ste 7107, Baltimore, MD 21287 (E-mail: gwhitman@jhmi.edu). 0022-5223/\$36.00

Copyright (c) 2014 Published by Elsevier Inc. on behalf of The American Association for Thoracic Surgery

http://dx.doi.org/10.1016/j.jtcvs.2013.08.024
}

the most commonly performed procedures in the United States. Although the heavy cost burden of coronary atherosclerosis on the health care system has been well studied, there is a paucity of literature identifying systematic factors that may contribute to variations in costs of coronary revascularization. In this study, we evaluated interhospital variability in inpatient costs of CABG in the United States.

\section{PATIENTS AND METHODS}

\section{Data Source}

The Nationwide Inpatient Sample was the data source used for this study. This registry was developed as part of the Agency for Healthcare Research and Quality Healthcare Cost and Utilization Project. It represents a $20 \%$ stratified sample of all hospitals within the United States, with patient-level data on approximately 8 million hospital stays per year from 1050 hospitals. ${ }^{2}$ Because the data are publically available and deidentified, the Johns Hopkins University School of Medicine Institutional Review Board granted the study exempt status.

\section{Inclusion and Exclusion Criteria}

CABGs performed between January 1, 2005, and December 31, 2008, were identified in the Nationwide Inpatient Sample using the International Classification of Diseases, Ninth Revision procedure codes 36.10 to 36.19. Inclusion criteria included adults aged 18 years or older and isolated CABGs. Patients undergoing $\mathrm{CABG}$ concomitant with other major surgery 


\section{Abbreviation and Acronym \\ $\mathrm{CABG}=$ coronary artery bypass grafting}

were, therefore, excluded. Urgent or emergent procedures and reoperative CABGs were included in the study population.

\section{Primary Outcome}

The primary outcome of interest was inpatient cost of CABG. Charges for each individual patient undergoing CABG were supplied by the data set. Cost-to-charge ratios developed by the Agency for Healthcare Research and Quality, using Centers for Medicare and Medicaid Services data, were then used to derive costs from hospital charges. Unique ratios are calculated for each individual hospital. Hospital costs were used as the primary outcome as opposed to charges because the latter reflects pricing decisions related to payer policies and other factors unrelated to resource use.

\section{Variation in Hospital-Specific Costs}

Inpatient costs of $\mathrm{CABG}$ were aggregated at the hospital level. To measure interhospital variability in costs, a mixed-effect linear regression model was created using variables associated with cost of CABG in univariate linear regression analysis (exploratory $P<.20$ ). All variables tested for potential inclusion in the model were associated with CABG cost in univariate analysis $(P<.20)$ and were, therefore, included in the final model. Patient-level variables included in the model were age, sex, primary payer status, and Charlson comorbidity index. The Charlson comorbidity index is a highly validated cumulative score based on patient comorbidities that is predictive of mortality, with higher scores representing higher comorbidity burdens. Operative variables in the model included elective versus urgent or emergent procedure, number of coronary vessels bypassed, use of cardiopulmonary bypass, use of the internal mammary artery, cardiac catheterization during the same admission, intra-aortic balloon pump, permanent pacemaker or implantable cardioverter-defibrillator, ventricular assist device as postcardiotomy support, extracorporeal membrane oxygenation, coronary angioplasty during same admission, non-drug-eluting or drugeluting coronary stent during same admission, and redo CABG. Complications that were included in the multivariable model were as follows: respiratory failure, pneumonia, acute renal failure, sepsis, stroke, pulmonary embolism, gastrointestinal tract bleed, wound complication, hemorrhage, and cardiac shock or arrest. Hospital-related variables included hospital region, teaching status, urban versus rural location, and annual hospital CABG volume. Although the analysis was limited to isolated CABGs, annual volume was inclusive of all CABGs, including those performed concomitant to another procedure, because this would be expected to add to the "overall experience" of the center in performing CABG. Length of hospitalization, in-hospital mortality, and the year the operation was performed were also included in the model.

These 34 covariates comprised the fixed-effect parameters in the mixedeffect linear regression model. The random-effect parameters were the individual hospitals. The SD of the hospital effect was calculated in the model to determine if there was significant between-center variability in costs of CABG after adjusting for the fixed-effect parameters. All statistical analyses were performed using STATA, version 11, software (StataCorp LP, College Station, Tex).

\section{RESULTS}

\section{Patient and Operative Characteristics}

A total of 183,973 isolated CABG patients were included in the analysis. The mean age was $65.2 \pm 10.8$ years
(Table 1). Most patients were males (73\%), with a primary payer status of Medicare $(52 \%)$ or private insurance $(40 \%)$. Half of the patients had a Charlson comorbidity score of 2 or greater $(47 \%)$. The most common comorbidities included myocardial infarction $(39 \%)$, diabetes mellitus $(31 \%)$, atrial fibrillation $(25 \%)$, congestive heart failure $(21 \%)$, and chronic obstructive pulmonary disease $(21 \%)$. A total of $9 \%$ of the study population had chronic renal insufficiency.

Regarding operative characteristics, most CABGs were done on an urgent or emergent basis (55\%) (Table 1). A total of $55 \%$ of patients had a cardiac catheterization during the same admission. Approximately half of the cases involved a 3- or more vessel bypass. The internal mammary artery was used as a conduit in $89 \%$, with $73 \%$ being performed on cardiopulmonary bypass. A total of $9 \%$ of patients required an intra-aortic balloon pump. The use of a permanent pacemaker or implantable cardioverterdefibrillator $(2 \%)$, ventricular assist device $(0.1 \%)$, or extracorporeal membrane oxygenation $(0.02 \%)$ was uncommon in the study population. Coronary angioplasty $(3 \%)$ or non-drug-eluting $(0.7 \%)$ or drug-eluting $(0.9 \%)$ coronary stent placement during the same admission was also uncommon.

\section{Hospital Characteristics}

There were 633 hospitals included in the analysis. Most patients were treated at teaching hospitals $(57 \%)$ in an urban setting (97\%) (Table 1). Hospital region included South $(44 \%)$, Midwest $(25 \%)$, West $(16 \%)$, and Northeast $(15 \%)$. The mean annual overall CABG volume was 441 \pm 340 per year.

\section{Mortality and Morbidity}

The overall unadjusted in-hospital mortality rate was $2.2 \%(\mathrm{n}=3967)($ Table 2$)$. As expected, this rate was lower in elective cases $(1.5 \%$ vs $2.7 \% ; P<.001)$. The mean length of hospitalization was $9.4 \pm 7.2$ days, with a median hospitalization of 7 days (interquartile range, 6-11 days). A major postoperative complication was observed in $36 \%$ $(\mathrm{n}=65,538)$ of the study population. Individual complication rates were as follows: respiratory failure $(17 \%$; $\mathrm{n}=31,081)$, pneumonia $(5 \% ; \mathrm{n}=9308)$, acute renal failure $(9 \% ; \mathrm{n}=17,136)$, sepsis $(1 \% ; \mathrm{n}=2351)$, stroke $(2 \%$; $\mathrm{n}=3096)$, pulmonary embolism $(0.4 \% ; \mathrm{n}=683)$, gastrointestinal tract bleed $(0.5 \% ; \mathrm{n}=853)$, wound complication $(2 \% ; n=3094)$, hemorrhage $(5 \% ; n=9299)$, and cardiac shock or arrest $(11 \% ; n=20,257)$.

\section{Costs}

The overall average inpatient cost of $\mathrm{CABG}$ was $\$ 37,924 \pm \$ 25,374$ per patient (Figure $1, A$ ). The average cost of a CABG at the hospital level was $\$ 40,424$, with the SD of average CABG cost between hospitals being 
TABLE 1. Patient, operative, and hospital characteristics of the study population

\begin{tabular}{|c|c|c|}
\hline Variable & $\begin{array}{c}\text { Study population } \\
(\mathrm{n}=183,973)\end{array}$ & Missing data \\
\hline \multicolumn{3}{|l|}{ Patient } \\
\hline Age, y & $65.2 \pm 10.8$ & $14(0.008)$ \\
\hline Male sex & $133,573(73)$ & $14(0.008)$ \\
\hline Payment status & & $260(0.1)$ \\
\hline Medicare & $95,287(52)$ & \\
\hline Private insurance & $73,367(40)$ & \\
\hline Medicaid & $8912(5)$ & \\
\hline Other & $6147(3)$ & \\
\hline Charlson comorbidity score & & $0(0)$ \\
\hline 0 & $38,420(21)$ & \\
\hline 1 & $59,675(32)$ & \\
\hline$>2$ & $85,878(47)$ & \\
\hline Comorbidities & & $0(0)$ \\
\hline Atrial fibrillation & $45,959(25)$ & \\
\hline Myocardial infarction & $71,663(39)$ & \\
\hline Congestive heart failure & $39,412(21)$ & \\
\hline Peripheral vascular disease & $21,096(11)$ & \\
\hline Cerebrovascular disease & $16,072(9)$ & \\
\hline COPD & $38,493(21)$ & \\
\hline Diabetes mellitus & $56,365(31)$ & \\
\hline Chronic renal insufficiency & $15,790(9)$ & \\
\hline Liver disease & $762(0.4)$ & \\
\hline \multicolumn{3}{|l|}{ Operative } \\
\hline Urgent or emergent case & $100,178(55)$ & $306(0.2)$ \\
\hline $\begin{array}{l}\text { No. of coronary vessels } \\
\text { bypassed }\end{array}$ & & $7750(4)$ \\
\hline 1 & $26,255(15)$ & \\
\hline 2 & $64,201(36)$ & \\
\hline 3 & $57,728(33)$ & \\
\hline$>4$ & $28,039(16)$ & \\
\hline Use of cardiopulmonary bypass & $133,748(73)$ & $0(0)$ \\
\hline $\begin{array}{l}\text { Use of internal mammary } \\
\text { artery }\end{array}$ & $163,136(89)$ & $0(0)$ \\
\hline $\begin{array}{l}\text { Cardiac catheterization during } \\
\text { admission }\end{array}$ & $101,052(55)$ & $0(0)$ \\
\hline Intra-aortic balloon pump & $17,366(9)$ & $0(0)$ \\
\hline $\begin{array}{l}\text { Permanent pacemaker or } \\
\text { implantable cardioverter- } \\
\text { defibrillator }\end{array}$ & $3133(2)$ & $0(0)$ \\
\hline $\begin{array}{l}\text { Ventricular assist device as } \\
\text { postcardiotomy support }\end{array}$ & $203(0.1)$ & $0(0)$ \\
\hline $\begin{array}{l}\text { Extracorporeal membrane } \\
\text { oxygenation }\end{array}$ & $37(0.02)$ & $0(0)$ \\
\hline $\begin{array}{l}\text { Coronary angioplasty during } \\
\text { admission }\end{array}$ & $5601(3)$ & $0(0)$ \\
\hline $\begin{array}{l}\text { Coronary stent during } \\
\text { admission }\end{array}$ & & $0(0)$ \\
\hline Non drug eluting & $1355(0.7)$ & \\
\hline Drug eluting & $1587(0.9)$ & \\
\hline
\end{tabular}

$\$ 12,130$ (Figure 1, B). Several significant predictors of cost were identified in the multivariable model (Table 3). After adjusting for multiple covariates, there persisted significant
TABLE 1. Continued

\begin{tabular}{lcc}
\hline \multicolumn{1}{c}{ Variable } & $\begin{array}{c}\text { Study population } \\
(\mathbf{n}=\mathbf{1 8 3 , 9 7 3})\end{array}$ & Missing data \\
\hline $\begin{array}{l}\text { Hospital } \\
\text { Teaching hospital } \\
\text { Region }\end{array}$ & $104,259(57)$ & $0(0)$ \\
$\quad$ Northeast & $27,108(15)$ & \\
$\quad$ Midwest & $45,625(25)$ & \\
$\quad$ South & $81,249(44)$ & \\
$\quad$ West & $29,991(16)$ & \\
Rural location & $6351(3)$ & $0(0)$ \\
Annual hospital CABG & $441 \pm 340$ & $0(0)$ \\
$\quad$ volume* & & \\
\hline $\begin{array}{l}\text { Data are given as mean } \pm \text { SD or number (percentage). COPD, Chronic obstructive } \\
\text { pulmonary disease; } C A B G, \text { coronary artery bypass grafting. *Annual volume inclu- }\end{array}$ \\
$\begin{array}{l}\text { sive of all CABGs performed by that hospital, including CABGs concomitant with } \\
\text { other procedures. }\end{array}$
\end{tabular}

variability between hospitals with respect to CABG cost $(P<.001)$ (Table 3 and Figure 2). The magnitude of the hospital effect was greater than all variables in the model, except for in-hospital mortality, postoperative sepsis, hospital region, ventricular assist device implantation as postcardiotomy support, need for extracorporeal membrane oxygenation, and permanent pacemaker or cardioverterdefibrillator implantation (Figure 2).

\section{DISCUSSION}

Although providing high-quality care with favorable clinical outcomes has been the cornerstone of evaluating surgical programs, there has been increasing emphasis on

TABLE 2. Outcomes of CABG in the study population

\begin{tabular}{lcc}
\hline \multicolumn{1}{c}{ Outcome } & $\begin{array}{c}\text { Study population } \\
(\mathbf{n}=\mathbf{1 8 3 , 9 7 3 )}\end{array}$ & Missing data \\
\hline In-hospital mortality & & \\
Overall & $3967(2)$ & $127(0.07)$ \\
Elective cases & $1227(1)$ & $55(0.07)$ \\
Urgent or emergent cases & $2735(3)$ & $72(0.07)$ \\
Length of hospitalization, d & & $0(0)$ \\
Mean \pm SD & $9.4 \pm 7.2$ & \\
Median (interquartile range) & $7(6-11)$ & \\
Complications & & \\
Overall & $65,538(36)$ & $0(0)$ \\
Respiratory failure & $31,081(17)$ & $0(0)$ \\
Pneumonia & $9308(5)$ & $0(0)$ \\
Acute renal failure & $17,136(9)$ & $0(0)$ \\
Sepsis & $2351(1)$ & $0(0)$ \\
Stroke & $3096(2)$ & $0(0)$ \\
Pulmonary embolism & $683(0.4)$ & $0(0)$ \\
Gastrointestinal tract bleed & $853(0.5)$ & $0(0)$ \\
Wound complication & $3094(2)$ & $0(0)$ \\
Hemorrhage & $9299(5)$ & $0(0)$ \\
Cardiac shock or arrest & $20,257(11)$ & $0(0)$ \\
\hline
\end{tabular}

Data are given as number (percentage) unless otherwise indicated. $C A B G$, Coronary artery bypass grafting; $S D$, standard deviation. 

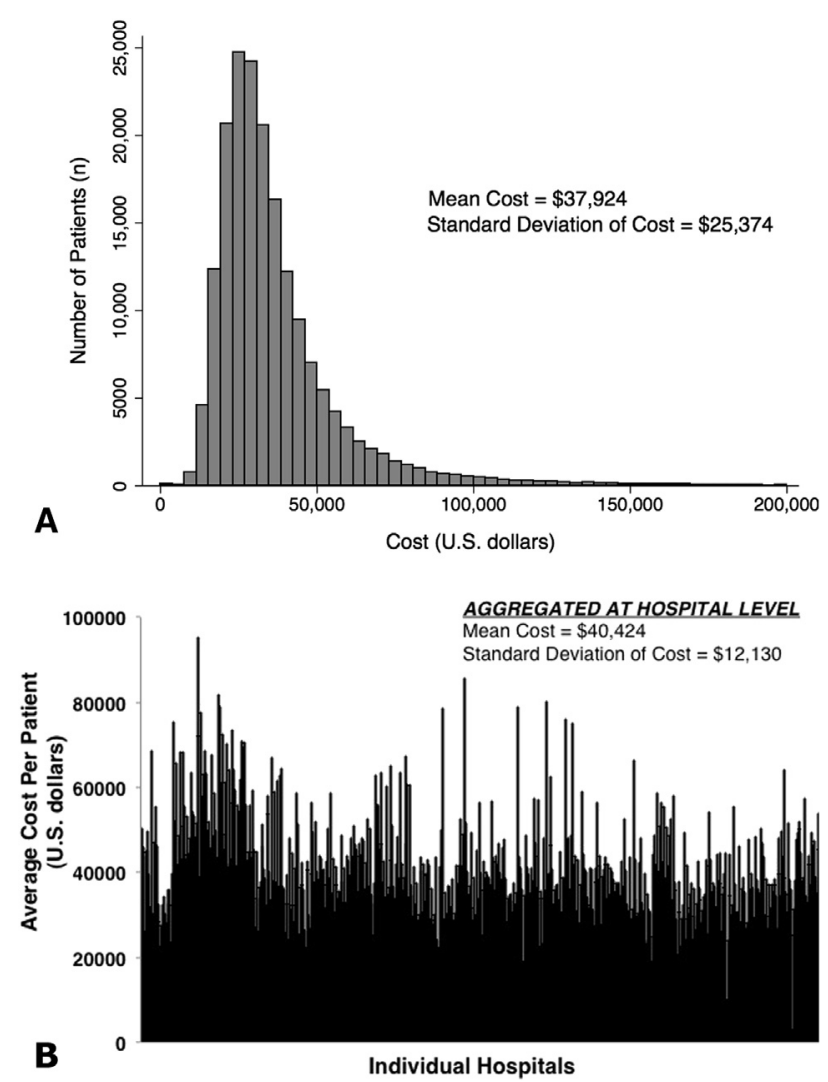

FIGURE 1. Histograms demonstrating the number of patients across the cost spectrum (A) and the average costs of coronary artery bypass grafting at the hospital level (B).

providing such care in an efficient manner. The inpatient costs associated with a procedure are one measure of efficiency. The costs of CABG, which remains one of the more commonly performed operations worldwide, have been shown to be higher in the United States than in other countries, without necessarily a clear advantage in clinical outcomes. ${ }^{3}$ In this study, we examined interhospital variability in costs of CABG in more than 180,000 patients in 633 hospitals in the United States.

\section{Variability in Costs of CABG Between Hospitals}

The principal finding of this large-cohort analysis was that, after accounting for multiple patient-, operative-, complication-, and hospital-level variables, there persisted significant variability in costs of performing CABG between hospitals. This suggests that, although different hospitals may provide comparable quality of care, there is a wide divergence in the pathways used to achieve that level of care, with differing associated costs. These data underscore the importance of identifying differences in practice patterns that may contribute to cost divergence. Implementation of specific cost-effective processes of care may then be used as a potential strategy for broader-scale cost containment.
A prior analysis of 21 hospitals performing CABG in New York State in 1992 demonstrated similar results as our study. ${ }^{4}$ After accounting for baseline patient risk, there persisted significant interhospital variability in costs, leading the authors to conclude that reductions in CABG cost could be achieved by standardizing clinical practice. A study of more than 90,000 Medicare patients undergoing CABG in 1990 demonstrated substantial geographic variability in patient-level costs and length of hospitalization. Another analysis examined nearly 500,000 CABGs in the Society of Thoracic Surgeons National Database and demonstrated wide variability between hospitals in lengths of hospitalization. ${ }^{6}$ Finally, a study of more than 6700 CABG patients in a statewide database found significant differences in resource use after accounting for patient characteristics, operative variables, and postoperative complications. $^{7}$ These prior reports, in conjunction with our data, emphasize the potential utility of standardizing clinical pathways as a means of reducing costs of care in CABG.

\section{Predictors of Cost}

The strongest predictors of increased cost in our analysis were the need for ventricular assist device implantation or extracorporeal membrane oxygenation. This finding is not unexpected given that the device, associated equipment, staffing, and operational costs of these cardiopulmonary support modalities are significant. In-hospital mortality was also a strong predictor of increased costs. This finding was again intuitive in that patients not surviving to discharge after an operation may have more complex procedures with increased operative times or greater intraoperative resource use, in addition to more complicated postoperative courses that may involve greater use of consult services and both noninvasive and invasive procedures. In parallel to our finding, a study of 1221 patients undergoing various cardiac procedures concluded that the highest costs were in patients with operative mortality, greater than the costs in patients with nonfatal morbidity or those with uncomplicated hospital stays. ${ }^{8}$

We also found that all complications included in our analysis, with the exception of wound complications, were associated with significantly increased costs of care. Postoperative sepsis was the costliest complication, followed by hemorrhage and respiratory tract failure. This finding is also intuitive in that the management of these specific complications is resource heavy, including prolonged intensive care unit stays, increased medication and blood product use, and additional procedures or reoperations. A study of Medicare beneficiaries undergoing CABG in 2005 similarly identified septicemia as being associated with the greatest incremental cost in care and the lengthiest prolongation of hospitalization of all complications studied. ${ }^{9}$ 
TABLE 3. Mixed-effect multivariable linear regression analysis for cost of CABG

\begin{tabular}{|c|c|c|}
\hline Covariates & $\begin{array}{c}\text { Coefficient } \\
(95 \% \text { confidence interval }) \\
\end{array}$ & $P$ value \\
\hline \multicolumn{3}{|l|}{ Fixed-effect parameters } \\
\hline Age (increasing, per y) & $-64(-71$ to -58$)$ & $<.001$ \\
\hline Male sex & 564 (448 to 680$)$ & $<.001$ \\
\hline \multicolumn{3}{|l|}{ Payment status } \\
\hline Private insurance & Reference & Reference \\
\hline Medicare & 146 (7 to 284$)$ & .04 \\
\hline Medicaid & $-790(-1040$ to -540$)$ & $<.001$ \\
\hline Other & $-297(-593$ to 0$)$ & .05 \\
\hline \multicolumn{3}{|l|}{ Charlson comorbidity score } \\
\hline 0 & Reference & Reference \\
\hline 1 & $137(-5$ to 280$)$ & .06 \\
\hline$>2$ & 186 (46 to 327$)$ & .009 \\
\hline Urgent or emergent case & 693 (575 to 811$)$ & $<.001$ \\
\hline \multicolumn{3}{|l|}{$\begin{array}{l}\text { No. of coronary vessels } \\
\text { bypassed }\end{array}$} \\
\hline 1 & Reference & Reference \\
\hline 1 & $622(466$ to 778$)$ & $<.001$ \\
\hline 3 & $1100(939$ to 1261$)$ & $<.001$ \\
\hline$>4$ & 1744 (1553 to 1934$)$ & $<.001$ \\
\hline Cardiopulmonary bypass & $411(272$ to 551$)$ & $<.001$ \\
\hline $\begin{array}{l}\text { Internal mammary artery } \\
\text { not used }\end{array}$ & 1104 (942 to 1267$)$ & $<.001$ \\
\hline $\begin{array}{l}\text { Cardiac catheterization } \\
\text { during admission }\end{array}$ & 1399 (1285 to 1513$)$ & $<.001$ \\
\hline Intra-aortic balloon pump & 7919 (7736 to 8101$)$ & $<.001$ \\
\hline $\begin{array}{l}\text { Permanent pacemaker or } \\
\text { implantable } \\
\text { cardioverter-defibrillator }\end{array}$ & $15,831(15,440$ to 16,221$)$ & $<.001$ \\
\hline $\begin{array}{c}\text { Ventricular assist device as } \\
\text { postcardiotomy support }\end{array}$ & $52,094(50,576$ to 53,612$)$ & $<.001$ \\
\hline $\begin{array}{l}\text { Extracorporeal membrane } \\
\text { oxygenation }\end{array}$ & $28,999(25,367$ to 32,630$)$ & $<.001$ \\
\hline $\begin{array}{l}\text { Coronary angioplasty } \\
\text { during admission }\end{array}$ & 6058 (5697 to 6420$)$ & $<.001$ \\
\hline $\begin{array}{l}\text { Non-drug-eluting stent } \\
\text { during admission }\end{array}$ & $3546(2889$ to 4204$)$ & $<.001$ \\
\hline $\begin{array}{l}\text { Drug-eluting stent during } \\
\text { admission }\end{array}$ & 6997 (6385 to 7609$)$ & $<.001$ \\
\hline Redo CABG & 484 (25 to 942$)$ & .04 \\
\hline Teaching hospital & 1963 (1405 to 2521$)$ & $<.001$ \\
\hline \multicolumn{3}{|l|}{ Hospital region } \\
\hline South & Reference & Reference \\
\hline Midwest & 3505 (1637 to 5372$)$ & $<.001$ \\
\hline West & $12,387(10,294$ to 14,480$)$ & $<.001$ \\
\hline Northeast & 4907 (2220 to 7593$)$ & $<.001$ \\
\hline Hospital in rural location & 5009 (1927 to 8091$)$ & .001 \\
\hline \multicolumn{3}{|l|}{ Complications } \\
\hline Respiratory failure & 3673 (3518 to 3828$)$ & $<.001$ \\
\hline Pneumonia & 2020 (1776 to 2265$)$ & $<.001$ \\
\hline Acute renal failure & 2417 (2229 to 2605$)$ & $<.001$ \\
\hline Sepsis & $11,303(10,826$ to 11,780$)$ & $<.001$ \\
\hline Stroke & $1188(794$ to 1581$)$ & $<.001$ \\
\hline Pulmonary embolism & 1194 (369 to 2019) & .005 \\
\hline
\end{tabular}

TABLE 3. Continued

\begin{tabular}{ccc}
\hline Covariates & $\begin{array}{c}\text { Coefficient } \\
(\mathbf{9 5} \% \text { confidence interval) }\end{array}$ & $\boldsymbol{P}$ value \\
\hline $\begin{array}{c}\text { Gastrointestinal tract } \\
\text { bleed }\end{array}$ & $1153(416$ to 1890$)$ & .002 \\
Wound complication & $65(-336$ to 466$)$ & .75 \\
$\quad$ Hemorrhage & $5260(5028$ to 5491$)$ & $<.001$ \\
$\quad$ Cardiac shock or arrest & $523(358$ to 688$)$ & $<.001$ \\
Annual hospital CABG & $768(399$ to 1134$)$ & $<.001$ \\
$\quad$ volume (decreasing, per & & \\
100 cases) & $2428(2419$ to 2437$)$ & $<.001$ \\
Length of hospitalization & & \\
(increasing, per d) & $16,758(16,391$ to 17,125$)$ & $<.001$ \\
In-hospital mortality & $-227(-297$ to -156$)$ & $<.001$ \\
Year of operation (more & & \\
recent, per y) & & $<.001$ \\
Random-effect parameter & & \\
Individual hospital effect & $9560(9035$ to 10,117$)$ & \\
\hline$C A B G$, Coronary artery bypass grafting. &
\end{tabular}

A higher comorbidity burden, more bypassed vessels, redo operation, and use of intra-aortic balloon pump also increased the cost of CABG in our analysis. These factors have been shown in prior studies to correlate with worse clinical outcomes and increased resource use. ${ }^{7,8,10}$ Not unexpectedly, longer hospital stays also correlated with greater costs in our multivariable model. We found that decreasing hospital CABG volume was associated with higher patient-level costs, a finding that has been demonstrated in a prior statewide analysis of isolated CABGs. ${ }^{11}$ Interestingly, this association was independent of patient characteristics and clinical outcomes in our model, suggesting that the cost savings at higher-volume institutions are not entirely explained by reductions in operative mortality or morbidity.

In addition, the use of cardiopulmonary bypass was associated with increased inpatient costs in the multivariable model. Off-pump CABG has been shown in prior studies to be associated with lower costs compared with on-pump CABG. ${ }^{12,13}$ Same admission cardiac catheterization, coronary angioplasty, and coronary stent placement were each associated with increased costs, presumably because of the additive costs of the procedures themselves, in addition to potentially higher risks of acute kidney injury and increased CABG complexity or mortality risk. ${ }^{10,14,15}$

\section{Limitations}

A major limitation of our study is that we were unable to itemize the specific costs of care because these were not available in the registry. Moreover, identifying the differences between hospitals with respect to individual components of overall cost, such as operating room costs, medication costs, or costs related to postoperative tests or procedures, may help shed more insight into the reasons for such wide variability among institutions. Although we 


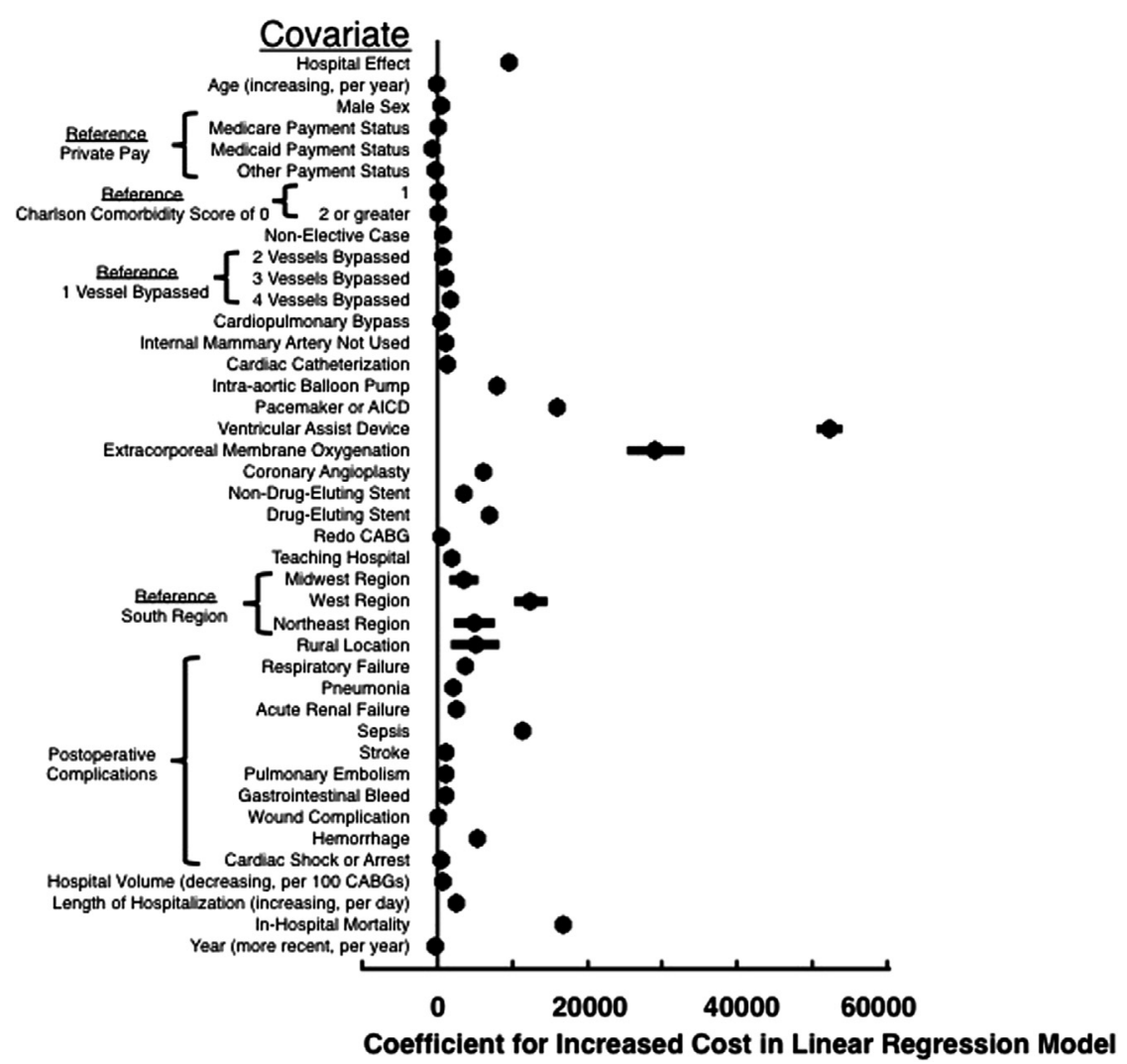

FIGURE 2. Forest plot depicting the results of the mixed-effect linear regression model for cost of coronary artery bypass grafting ( $C A B G)$. $A I C D$, Automated implantable cardioverter defibrillator.

used unique cost-to-charge ratios developed by the Agency for Healthcare Research and Quality for each individual hospital, accurately assessing true costs is challenging and susceptible to accounting-related and other errors. In addition, there may be other clinical factors not included in the Nationwide Inpatient Sample that affect costs but were unable to be accounted for in our multivariable model.

Another important limitation was that early readmissions after discharge and their associated costs were not included in this analysis. Although controversial, it is conceivable that hospitals with fast-track pathways for early discharge after CABG may have lower costs during that particular admission, but this may come at the expense of higher readmission rates. ${ }^{16,17}$ Capturing these patients would be important to gain a sense of the true overall costs of CABG. We also did not include longer-term costs related to patients requiring outpatient nursing or being discharged to facilities that provide extended care. These factors contribute to the overall cost of CABG but were not available for inclusion in our analysis. ${ }^{17,18}$

Finally, the Nationwide Inpatient Sample is an administrative database and there are limitations in conducting analyses using clinical parameters with such databases. In comparing our study population characteristics with those presented in an analysis of isolated CABGs from the Society of Thoracic
Surgeons' Database, the use of the internal mammary artery was lower and the use of off-pump CABG was higher in our data. ${ }^{19}$ The proportion of cases performed on an urgent or emergent basis or requiring a preoperative intra-aortic balloon pump was similar. Although the discrepancies may be the result of differences between hospitals participating in the Society of Thoracic Surgeons Database and nationwide practice patterns, it may also be because of differences between administrative and clinical registries.

\section{CONCLUSIONS}

This study of more than 180,000 patients at 633 hospitals in the United States demonstrates a substantial degree of variability in costs of CABG between institutions. We determined that individual hospital centers, independent of multiple patient- and outcome-specific factors, are drivers of these differences. Comparison of hospital-specific behavior with identification of the causes of cost discrepancies represents an opportunity for standardization of care and improvement in resource use.

\section{References}

1. Squires DA. Explaining high health care spending in the United States: an international comparison of supply, utilization, prices, and quality. Issue Brief (Commonw Fund). 2012;10:1-14. 
2. Healthcare Quality and Utlitization Project. Overview of the Nationwide Inpatient Sample. Available at: http://www.hcup-us.ahrq.gov/nisoverview.jsp. Accessed March 25, 2013.

3. Eisenberg MJ, Filion KB, Azoulay A, Brox AC, Haider S, Pilote L. Outcomes and cost of coronary artery bypass graft surgery in the United States and Canada. Arch Intern Med. 2005;165:1506-13.

4. Cowper PA, DeLong ER, Peterson ED, Hannan EL, Ray KT, Racz M, et al. Variability in cost of coronary bypass surgery in New York State: potential for cost savings. Am Heart J. 2002;143:130-9.

5. Cowper PA, DeLong ER, Peterson ED, Lipscomb J, Muhlbaier LH, Jollis JG, et al; IHD Port Investigators. Geographic variation in resource use for coronary artery bypass surgery. Med Care. 1997;35:320-33.

6. Peterson ED, Coombs LP, Ferguson TB, Shroyer AL, DeLong ER, Grover FL, et al. Hospital variability in length of stay after coronary artery bypass surgery: results from the Society of Thoracic Surgeon's National Cardiac Database. Ann Thorac Surg. 2002;74:464-73.

7. Ghali WA, Hall RE, Ash AS, Moskowitz MA. Identifying pre- and postoperative predictors of cost and length of stay for coronary artery bypass surgery. Am J Med Qual. 1999; 14:248-54.

8. Ferraris VA, Ferraris SP, Singh A. Operative outcome and hospital cost. J Thorac Cardiovasc Surg. 1998;115:593-602.

9. Brown PP, Kugelmass AD, Cohen DJ, Reynolds MR, Culler SD, Dee AD, et al. The frequency and cost of complications associated with coronary artery bypass surgery: results from the United States Medicare program. Ann Thorac Surg. 2008;85:1980-6.

10. Shahian DM, O'Brien SM, Filardo G, Ferraris VA, Haan CK, Rich JB, et al. The Society of Thoracic Surgeons 2008 cardiac surgery risk models: part 1-coronary artery bypass grafting surgery. Ann Thorac Surg. 2009;88:S2-22.

11. Saleh SS, Racz M, Hannan E. The effect of preoperative and hospital characteristics on costs for coronary artery bypass graft. Ann Surg. 2009;249:335-41.

12. Puskas JD, Williams WH, Mahoney EM, Huber PR, Block PC, Duke PG, et al. Offpump vs conventional coronary artery bypass grafting: early and 1-year graft patency, cost, and quality-of-life outcomes: a randomized trial. JAMA. 2004;291:1841-9.

13. Al-Ruzzeh S, Epstein D, George S, Bustami M, Wray J, Ilsley C, et al. Economic evaluation of coronary artery bypass grafting surgery with and without cardiopulmonary bypass: cost-effectiveness and quality-adjusted life years in a randomized controlled trial. Artif Organs. 2008;32:891-7.

14. Del Duca D, Igbal S, Rahme E, Goldberg P, de Varennes B. Renal failure after cardiac surgery: timing of cardiac catheterization and other perioperative risk factors. Ann Thorac Surg. 2007:84:1264-71

15. Kramer RS, Quinn RD, Groom RC, Braxton JH, Malenka DJ, Kellett MA, et al. Same admission cardiac catheterization and cardiac surgery: is there an increased incidence of acute kidney injury? Ann Thorac Surg. 2010;90:1418-23.

16. Li Y, Cai X, Mukamel DB, Cram P. Impact of length of stay after coronary bypass surgery on short-term readmission rate: an instrumental variable analysis. Med Care. 2013;51:45-51

17. Lazar HL, Fitzgerald CA, Ahmad T, Bao Y, Colton T, Shapira OM, et al. Early discharge after coronary artery bypass surgery: are patients really going home earlier? J Thorac Cardiovasc Surg. 2001;121:943-50.

18. Swaminathan M, Phillips-Bute BG, Patel UD, Shaw AD, Stafford-Smith M, Douglas PS, et al. Increasing healthcare resource utilization after coronary artery bypass graft surgery in the United States. Circ Cardiovasc Qual Outcomes. 2009; 2:305-12.

19. EIBardissi AW, Aranki SF, Sheng S, O'Brien SM, Greenberg CC, Gammie JS. Trends in isolated coronary artery bypass grafting: an analysis of the Society of Thoracic Surgeons adult cardiac surgery database. J Thorac Cardiovasc Surg. 2012;143:273-81

\section{Discussion}

Dr T. Bruce Ferguson (Greenville, NC). I would like to congratulate Dr Kilic and his coauthors on an important study using the National Inpatient Sample. This is something that we have started doing more and more frequently, and this is an elegant analysis using that rich data resource. As well, the findings of your study are actually provocative in supporting something we have suspected for some time, while also introducing some new thoughts into the equation.
You indicated in your paper and in the presentation that $30 \%$ of the overall variability in cost is driven by the nature of the environment in which the services are delivered. You conclude that the variability, by any criteria, is excessively high. This is a health policy issue that CMS would look at and say variability is bad, and we need to figure out why.

The other part of your interesting data, however, focused on inhospital issues related to mortality, including sepsis and some things we normally would not think of as necessarily driving health care costs in coronary bypass surgery. It is not surprising to me that the VAD patients and the ECMO patients generated the highest costs, but, fortunately, they occur infrequently.

So, I have 2 questions for you, 1 in each area.

At the health policy level, if we as stewards of our specialty can look and see that there is this huge variability in the cost of coronary bypass surgery across this sampling of hospitals across the country, what can we do at the specialty level that would generate information at the health policy level that would reduce that level of the variation and excess in health care costs?

And the second question is, in terms of the in-hospital mortality and the single greatest cause of morbidity, which is sepsis, what could we do at the local level to be able to drive those costs down? Can we fix sepsis by putting central lines in safely and preventing pneumonia and doing MRSA screening and so forth? Do we really think about reducing health care costs when we do these things? And is there a point at which we say to a patient who is going to die and their family, I am sorry, we cannot really do anything else? Particularly when this occurs so infrequently?

Your study is provocative in raising these 2 important issues.

Dr Kilic. Thank you, Dr Ferguson, for those comments and questions. To address your first question about health policy implications, I think what this study does is really serves as a platform to demonstrate statistically that there is a significant variability between institutions with respect to costs of CABG. The future steps will be to identify specifically what processes of care are different between those institutions, because what these data identify is that there may be a comparable quality of care in terms of hard data, such as mortality and morbidity, between institutions, but the pathways that are used to achieve that level of care are significantly different, with significantly differing costs. So, what this does is really just serves as a platform, and we need to do more investigation to figure out what the specific processes are that are contributing to these differing costs.

With respect to your second question about sepsis and mortality, again, when we are talking about evaluating providers or evaluating programs, the gold standard should be the outcomes and not surrogates for outcomes such as costs. So, I think the ultimate responsibility should be to provide good quality of care with low mortality and low morbidity, and these data sort of expectedly show that sepsis, which is going to result in prolonged ICU stays and greater resource utilization, is a significant driver of cost. That is not to say that we would not potentially be able to look at how different institutions manage sepsis, their adherence to clinical guidelines, to see if there is some type of divergence in how those specific complications are managed to see if that may be contributing to the differing costs as well, and I think the same things apply for the in-hospital mortality. 
Dr Ferguson. One of the implications of your data and study in the health care environment, which is evolving in the United States, is that providers are only going to get paid for better quality care and lower-cost care. So, addressing both of those issues is going to become important if we are going to reduce the $30 \%$ variability across the providers; the alternative is that there will be many fewer places doing coronary bypass surgery.

Nice paper, and my congratulations to the authors.

Dr Kilic. Thank you.

Dr George Magovern (Pittsburgh, $\mathrm{Pa}$ ). Would you further define how you determined cost? Is cost a function of the charges that a hospital agrees to or are they actual costs of the procedure?

Dr Kilic. Thank you for that question. The Nationwide Inpatient Sample will actually provide the charges in the data set, and the AHRQ has specific costtocharge ratios that they develop for each individual hospital. So, utilizing that ratio, we are able to derive actual costs, which we believe are a better reflection of actual resource utilization versus the charges, which can affect payer policies and other things not related to resource utilization.

Dr Magovern. My second question is that as you decrease the cost and increase the efficiency of coronary bypass surgery and move it out into smaller hospitals, you also then make it more difficult to innovate or improve upon an operation. Specifically, how will small-volume centers learn to do off-pump coronary surgery or robotic coronary procedures?

In conclusion, most operative procedures evolve over time. Thus, surgeons need to find a balance between lowering costs and decreasing variability on one hand and improving outcomes with improvements in the operation with minimally invasive techniques, robotics, etc.

Dr Kilic. That is an excellent point.

Dr Claudio Muneretto (Brescia, Italy). I congratulate the authors for a nice paper. I did not find atrial fibrillation as a risk factor for increasing cost. Many previous studies demonstrate that atrial fibrillation made longer the stay in the hospital, made higher the consultant cost for several physicians, and, in addition, increases significantly stroke rate, renal failure, and low cardiac syndrome. Could you comment on that?

Dr Kilic. That is a great question regarding atrial fibrillation and why that was not depicted as a predictor of cost. We actually did not include the individual diagnostic comorbidities in the mixed-effect linear regression model. Instead, what we utilized was the Charlson comorbidity score, which is a cumulative score that incorporates all those comorbidities into one index. But, I think it may be a good point to go and look back at the specific comorbidities and see which ones tend to be the drivers of cost.

Dr A. Pieter Kappetein (Rotterdam, The Netherlands). Thank you much. Excellent paper. My question is also related to the previous issue. Why did you use the Charlson comorbidity index and not, for example, the STS score? Are there certain advantages or disadvantages to one of these scores?

Dr Kilic. Ideally, we would like to use something like the STS score. Unfortunately, many of those variables that are in the STS CABG risk model are not available in the NIS registry. So, it would just simply be a limitation of the database. But, again, I do think it would be worth going back and looking at the specific comorbidities and see if there are individual ones that seem to drive costs more than the others. 